\title{
COMPETÊNCIAS DO BIBLIOTECÁRIO ATUANDO COMO GESTOR NA BIBLIOTECA ESCOLAR
}

\author{
Khadidja de Brito Cartaxo ${ }^{1}$ \\ Universidade Candido Mendes \\ khadidjacartaxo@hotmail.com \\ Lucineide Lima ${ }^{2}$ \\ Universidade Federal do Ceará \\ professoraluhlima@gmail.com . \\ Lucas Almeida Serafim ${ }^{3}$ \\ Universidade Federal do Ceará \\ lucas.almeida@ufca.edu.br.
}

\begin{abstract}
Resumo
A biblioteca escolar é um espaço fundamental no processo de ensino aprendizagem, responsável em despertar no aluno o gosto pela leitura, para que ele possa adquirir conhecimento e se tornar assim um cidadão autocritico. Esta pesquisa visa mostrar a importância do profissional bibliotecário enquanto gestor de um espaço e o seu papel na formação de novos usuários. Como resultado dessa pesquisa foi observado que outros profissionais com formação em outras áreas atuam nas bibliotecas escolares, fazendo com que assim, a presença do profissional bibliotecário torne-se dispensável. A partir dessa pesquisa pode-se concluir que há uma carência de profissionais bibliotecários no que diz respeito a gestão pública, não existindo nenhum bibliotecário atuando nas escolas municipais, havendo somente professores readaptados a frente das bibliotecas. Isso se revela algo preocupante, pois por não ser o profissional certo para exercer a função, muitas vezes não há o empenho e nem interesse em fazer com que o espaço funcione de maneira correta, fazendo com que não desperte o interesse por parte do aluno e da comunidade escolar.
\end{abstract}

Palavras-chave: Gestão. Bibliotecário. Biblioteca Escolar

\section{LIBRARY SKILLS ACTING AS MANAGER IN THE SCHOOL LIBRARY}

\begin{abstract}
The school library is a fundamental space in the teaching-learning process, responsible for awakening in the student the taste for reading, so that he can acquire knowledge and thus become a self-critical citizen. This research aims to show the importance of the librarian as a manager of a space and its role in the formation of new users. As a result of this research it was observed that other professionals with training in other areas work in school libraries, thus making the presence of the professional librarian becomes dispensable. From this research it can be concluded that there is a shortage of professional librarians in public management, there is no librarian working in municipal schools, there are only teachers readapted ahead of the libraries. This reveals to be something worrisome, because because it is not the right professional to perform the function, often there is no commitment or interest in making the space work properly, causing it to not arouse the interest of the student and the school community.
\end{abstract}

Keywords: Management. Librarian. School Library.

\footnotetext{
${ }^{1}$ Especialista em gestão de Bibliotecas Públicas e Escolares

${ }^{2}$ Mestranda em Biblioteconomia.

${ }^{3}$ Docente do programa de pós-graduação em Biblioteconomia
} 


\section{INTRODUÇÃO}

A Biblioteca escolar é um espaço fundamental para o desenvolvimento do processo de ensino - aprendizagem dos alunos, funcionando assim como uma extensão da sala de aula, auxiliando também professores, coordenadores pedagógicos e gestores. A biblioteca escolar proporciona informação e ideias que são fundamentais para uma corroboração da promoção a leitura na sociedade contemporânea com base em informações e conhecimento. "A biblioteca proporciona aos alunos competências para a aprendizagem ao longo da vida e ajuda a desenvolver a sua imaginação, permitindo-lhes realizar-se na vida como cidadãos responsáveis" (UNESCO, 2011, p.1).

Contudo, para que a biblioteca escolar tenha êxito em suas competências, é necessário que a sua equipe seja formada por profissionais qualificados e que possuam formação na área. No espaço escolar, professores e bibliotecários deverão trabalhar juntos para desenvolver ações que estimulem o prazer pela busca do conhecimento, através da leitura.

O bibliotecário escolar tem uma grande responsabilidade com o funcionamento da biblioteca, pois os resultados das ações desenvolvidas dependerão dele.

Para atuar como bibliotecário escolar o profissional escolar deve ter noções mínimas de seu papel como educador e gestor, deve saber que lhe compete oferecer oportunidades, materiais e atividades especificas visando despertar o interesse dos usuários pela biblioteca para a partir daí poder trabalhar o desenvolvimento da leitura. (LIMA, 2014, p. 13).

É preciso que estes profissionais estejam preparados para enfrentar as mudanças ocorridas na sociedade, para assim atender as necessidades dos seus usuários. Para Rocha (2000, p. 1) o profissional bibliotecário “[...] no processo de conscientização e busca, vai descobrindo a dimensão de suas possibilidades e necessidades, bem como as formas de superálas, mediante sua participação na sociedade".

Diante do exposto, esta pesquisa tem como objetivo demonstrar a importância do bibliotecário enquanto gestor de um espaço e como agente intermediário do saber, assim como destacar suas competências. O interesse surgiu pela experiência dos pesquisadores enquanto atuantes na área de biblioteconomia, um deles desenvolve ações na Secretaria de Educação do Município de João Pessoa - PB tendo acesso às bibliotecas ou sala de leitura como é chamado por alguns diretores das escolas, onde percebeu-se que nenhuma escola municipal de João Pessoa, possui um bibliotecário, somente professores readaptados ${ }^{4}$.

\footnotetext{
${ }^{4}$ Professores que não podem mais assumir salas de aula, por motivo de doença.
} 
Surge assim a ideia de fazer um estudo comparativo entre a gestão de duas bibliotecas escolares, uma particular e outra pública, e o papel do profissional a frente delas. Acredita-se que esta pesquisa é importante para a área da Biblioteconomia, pois no remete ao que diz a lei 12.244/2010, que fala sobre a universalização das bibliotecas escolares.

\title{
2 BIBLIOTECA ESCOLAR
}

As bibliotecas possuem um papel importante na educação de todas as pessoas. Elas têm por finalidade apoiar, fomentar e fortalecer o projeto pedagógico das escolas. Além de estimular a leitura no cotidiano e proporcionar condições para que o professor/educador desenvolva e promova o acesso ao conhecimento. Para Perucchi (1999) "a biblioteca escolar deve ter papel de destaque no processo educativo, devido às várias informações e materiais que pode oferecer." A autora afirma a importância que uma biblioteca escolar tem no processo de ensinoaprendizagem.

As criações das primeiras bibliotecas no Brasil se deram no período colonial com a chegada dos jesuítas que se alojaram no país com o intuito de educar os colonos e catequizar os índios.

Carvalho e Silva (2009) dizem que a história dessas bibliotecas tem seus primórdios nos colégios religiosos, especialmente nos dos jesuítas que aqui foram chegando, em caráter particular na Bahia, por volta de 1549 chefiados por Manoel da Nóbrega. Os padres Jesuítas que vinham da Europa traziam livros que eram utilizados nesse processo, mas as obras que chegavam não eram suficientes. Com a vinda dos livros, os padres passaram a utilizar os acervos das bibliotecas dos conventos na alfabetização de indígenas e dos fillhos dos colonos. (MORAIS, 1979).

Contudo, os colégios Jesuítas não foram os únicos que desenvolveram atividades em bibliotecas escolares. A partir do século XVII, outras bibliotecas foram se instalando no Brasil, introduzidas por novas ordens religiosas. De acordo com Carvalho Silva (2010, p. 23-24):

\begin{abstract}
Podem ser destacadas, além dos jesuítas, as ordens dos franciscanos, beneditinos e carmelitas, que chegaram já em meados do século XVII (ou mesmo que tenham seus registros atestados a partir desse século). A prova de que outras ordens forneceram suas contribuições está nos seus métodos de estudos. Os franciscanos, por exemplo, agregaram métodos de valores experimentais das ciências, valorizando os estudos de ideais franceses, representados, sobretudo pela ideia da ilustração, enquanto os métodos jesuíticos eram essencialmente escolásticos.
\end{abstract}

As bibliotecas Jesuítas, assim como as Franciscanas e as beneditinas foram se espalhando pelo país em lugares como Rio de Janeiro, São Paulo, Maranhão e entre outros 
locais. Após este período se espalhou em inúmeros Estados os mais diversos tipos de bibliotecas, escolares, universitárias, especializadas entre outras, em crescimento constante até o século atual, apesar de toda tecnologia o livro impresso ainda é a melhor opção para diversos usuários (MARQUES, 2014).

As bibliotecas escolares possuem um papel fundamental no que diz respeito ao ensino aprendizagem dos alunos, auxiliando também a comunidade escolar (professores, gestores, especialistas, coordenadores pedagógicos, pais). Ela deve ser um organismo vivo dentro da escola, participar efetivamente na construção do currículo escolar, devendo assim, deixar de ser muitas vezes aquele espaço em o aluno é enviado para ficar de castigo ou servir como depósito para entulhos. A biblioteca deve ser vista como uma extensão da sala da aula.

\subsection{COMPETÊNCIAS E FORMAÇÃO DO BIBLIOTECÁRIO}

A formação profissional de qualquer indivíduo envolve aspectos que compreendem questões sobre ética, empregabilidade e conceitos sobre a profissão. Walter (2008, p. 87) diz que "a formação é fundamental para atender tantos aos anseios da sociedade quanto aos do próprio individuo que escolheu, por algum motivo, seguir determinada carreira”.

A área que o bibliotecário atua compreende fundamentalmente responsabilidades com a preservação, tratamento e disseminação da informação. A profissão do bibliotecário passou por uma grande evolução devido às novas tecnologias e da grande quantidade de informações que foram inseridas na internet. É uma área em expansão acelerada, motivadas por mudanças sociais e avanços tecnológicos, demandando atualização constante e diversidade muito grande de conhecimento e competências. (MUELLER, 1989).

Uma biblioteca deve estar sempre pronta para atender bem seu público e para isso sua equipe precisa ser bem preparada e atualizada, assim o profissional bibliotecário é de fundamental importância para que a biblioteca atinja os seus objetivos e o usuário saia satisfeito. Entre as principais funções do bibliotecário está a disseminação da informação e o estímulo à frequência e utilização da biblioteca, cabendo a ele atender as demandas e necessidades de informações dos usuários. Também deve atuar como gestor da informação e gestor de pessoas.

\footnotetext{
Nesse contexto, atuando como gestor escolar, o bibliotecário precisa ter como principal objetivo atender as expectativas dos usuários oferecendo um serviço de boa qualidade no atendimento e acervo colocando a disposição dos mesmos um ambiente que favoreça o desenvolvimento da aprendizagem, leitura e consequentemente novas descobertas proporcionadas através dos livros ou outros meios de informações que possam existir dentro do acervo. (LIMA, 2014, p.12).
} 
Com o surgimento de novas tecnologias da informação, o profissional da biblioteca precisou ampliar seus conhecimentos, deixando para trás aquele antigo conceito que o bibliotecário servia apenas para guardar livro em estantes, passando a ampliar seus horizontes para a nova realidade. Lima (2010) diz que o novo perfil do bibliotecário - gestor é um misto de várias profissões. A partir desse novo olhar, o bibliotecário passa a ter novos compromissos e recursos para desempenhar suas atribuições diante desta nova e emergente sociedade, sendo visto como um profissional mutável.

\subsection{GESTÃO EM BIBLIOTECAS}

De acordo Granados Molina (2001) a área de biblioteconomia sempre esteve intimamente ligada com o cliente, e essa interação entre biblioteca e usuário é o pilar no desenvolvimento de percepção de valor, confiança e compromisso. O bom funcionamento de uma biblioteca, se dá primeiramente pelo desempenho do profissional que está administrando. As bibliotecas devem sempre buscar novas estratégias, incluindo os usuários em seus serviços e sendo ele o principal foco.

A aplicação de uma gestão de qualidade em uma biblioteca pode contribuir em larga escala para o desenvolvimento de suas atividades, além de auxiliar nas necessidades de seus usuários. "A gestão preconiza a qualidade de serviços com foco na eficiência e na eficácia, buscando a rapidez e o resultado satisfatório que atenda às necessidades de informação dos usuários" (BEHR, 2008). Os autores fazem referência à importância de uma gestão baseada em ferramentas que facilitem o acesso dos usuários.

Contudo para que o sistema de gestão em qualidade seja colocado em prática e obter assim melhores resultados, é necessário que as bibliotecas façam um estudo de caso com o usuário, estando atendo as suas expectativas e necessidades. Algumas bibliotecas adotam padrões de certificadoras, como por exemplo, utilizam as certificações de ISO.

\section{METODOLOGIA}

O estudo se insere nos pressupostos dos métodos qualitativos de investigação. Segundo Kirk e Miller (1986), eles têm sido utilizados nas Ciências Sociais envolvendo a observação de pessoas em seus territórios e a interação com essas pessoas em suas próprias linguagens, buscando compreender a natureza do objeto considerando o contexto dos fenômenos. 
Para poder estudar o gerenciamento das bibliotecas, assim como a importância do bibliotecário nesse espaço, irei fazer entrevistas e utilizar trabalhos já publicados anteriormente, fazendo assim, uma revisão de literatura.

Utilizou-se como instrumento básico para a pesquisa, entrevista com questionário semiestruturado "(...) que combina perguntas fechadas e abertas, em que o entrevistado tem a possibilidade de discorrer sobre o tema em questão sem se prender a indagação formulada" (MINAYO, 2008, p. 5).

A técnica de observação será utilizada “(...) pelo contato direto do pesquisador com o fenômeno observado, para obter informações sobre a realidade dos atores sociais em seu próprio contexto" (CRUZ NETO, 1994, p.52), assim, poderei compreender as diferentes formas de trabalho dos agentes observados para poder na pesquisa utilizar o método comparativo, Gil (2008) comenta que o método comparativo procede pela investigação de indivíduos, classes, fenômenos ou fatos, com vistas para ressaltar as diferenças e as similaridades entre eles. Esse método realiza comparações com o objetivo de verificar semelhanças e divergências.

\section{RESULTADOS E DISCUSSÃO}

A escola exerce um papel fundamental na formação dos alunos, sendo ela responsável pela construção do conhecimento e na transformação desses alunos em seres críticos. De acordo com Amato e Garcia (1989) para que os objetivos da educação possam ser atingidos é necessário que os meios utilizados sejam compatíveis e eficazes. Portanto, a biblioteca encontra-se como um dos meios para a busca do conhecimento, inserido na escola, sendo ela um recurso indispensável.

"Reunidos no espaço da biblioteca escolar, os recursos informacionais irão se constituir num rico manancial para propiciar o desenvolvimento de conhecimentos, habilidades e atitudes para viver e conviver na sociedade da informação" (KUHLTHAU, 2013, p. 11). Inserido nesse meio, encontra-se o bibliotecário escolar, que tem como "missão" ser o agente intermediário desse saber.

Assim, diante do que foi exposto, minha pesquisa buscou fazer uma análise comparativa entre a gestão de uma biblioteca escolar pública e uma privada. Os objetos de estudo foram a biblioteca (sala de leitura) da Escola Municipal Almirante Barroso e a biblioteca da escola particular Evolução (Biblioteca Manoel Bandeira), ambas na cidade de João Pessoa - PB. Em visita as bibliotecas, pude observar a rotina do ambiente, a organização do acervo e qual público que a utiliza (faixa etária, ano, tipo de leitura). Na ocasião, um questionário foi aplicado com 
as bibliotecárias (a escola Evolução possui 02 bibliotecárias e a escola Almirante Barroso possui 02 professoras readaptadas).

A escola Almirante Barroso funciona no bairro de Cruz das Armas, atende os três turnos com ensino fundamental I, II e EJA (Educação de Jovens e Adultos), sua biblioteca é bem pequena, a sala é composta por algumas estantes espalhadas pelo espaço e duas mesas com quatro cadeiras cada, o acervo é composto por livros didáticos, literatura infantil e infantojuvenil, mapas, enciclopédias e outros materiais educativos, como jogos. Já a escola Evolução fica situada no bairro do Miramar, funciona pela manhã e tarde e atende a alunos desde a educação infantil, até o ensino médio. Sua biblioteca possui um grande espaço, composto por algumas salas, com um acervo muito rico, entre livros didáticos e literários, incluindo obras raras.

Fazendo uma pesquisa comparativa, podemos analisar as diferenças entre ambas, contudo a discrepância mais gritante é o fato de que a frente da biblioteca particular se encontram duas bibliotecárias, enquanto na biblioteca pública duas professoras readaptadas, que apesar de fazerem um bom trabalho, não possuem a formação que a profissão exige.

A respeito disso Perucchi (1999) diz:

Mas sabe-se que a maioria das escolas públicas brasileiras não possui biblioteca e as que possuem, estão em estado calamitoso de funcionamento, seja em nível de organização ou de atualização de acervos. Esta situação de caos é complementada por uma distorção das funções do bibliotecário dentro da escola, uma vez que a biblioteca geralmente é conduzida e controlada, não por um especialista, mas por um professor em fase de se aposentar ou em função remanejada, que o priva da sala de aula.

Isso nos leva a uma grande discussão sobre o assunto, principalmente por que não percebemos da esfera pública, uma tentativa de enquadrar-se a lei 12.244/2010, que mesmo com um prazo até 2020, não vemos perspectivas de mudanças.

Com relação a aquisição do acervo, ambas possuem um acervo muito rico e de vários formatos (livros, CDS, DVDS), contudo as formas de aquisição são bem distintas, no caso da biblioteca escola Almirante Barroso, o acervo é em sua grande maioria enviado pelo MEC (Ministério de Educação), sem nenhuma escolha por parte da escola. Porém, essa forma foi alterada, agora os gestores e professores participam da escolha dos livros literários que irão compor as bibliotecas. Outra forma de aquisição é via doação.

Já na biblioteca Manoel Bandeira, as bibliotecárias atuam efetivamente na escolha do acervo, havendo também participação dos alunos, sendo finalizado pelo setor financeiro da instituição, contudo, as profissionais têm total autonomia para as escolhas. Também aceitam doação, mas passa por um criterioso processo para saber se o conteúdo é adequado. 
As duas bibliotecas apresentam projetos que incentivam os alunos ao hábito da leitura, todo fim de semestre a profissional da sala de leitura (profissional da escola) deve enviar um relatório com as ações desenvolvidas para a Secretaria de Educação do Município - SEDEC e deve ser aprovado pelos profissionais do setor de Ensino Fundamental.

Diante do questionário realizado, foi possível perceber uma grande diferença entre a gestão das duas bibliotecas, na biblioteca da escola privada percebe-se uma maior autonomia para gerir o espaço, passando pela aquisição do acervo, pela gestão de pessoas envolvidas no trabalho e pela forma de trabalhar. Existe uma liberdade que não se pode enxergar na esfera pública, até porque existe um excesso burocrático que muitas vezes atrapalha o bom andamento de um trabalho.

\section{CONSIDERAÇÕES FINAIS}

A biblioteca e a escola são dois ambientes que não se separam. A biblioteca escolar deve ser um ambiente dinâmico e diversificado, para que assim, o aluno se sinta fascinado pelo saber e se torne um cidadão com senso crítico. Contudo, para que haja um bom resultado nesse processo, é necessário que exista um profissional qualificado à frente da biblioteca. $\mathrm{O}$ Bibliotecário deve ser o agente intermediário entre o conhecimento e o aluno.

Nessa pesquisa procurou-se demostrar a importância do bibliotecário enquanto gestor de um espaço, assim como fazer um estudo comparativo entre a gestão de um bibliotecário que exerce sua profissão em uma biblioteca de uma escola particular e um profissional da sala de leitura de uma escola municipal, ambas na cidade de João Pessoa.

A partir dessa pesquisa pode-se concluir que há uma carência de profissionais bibliotecários no que diz respeito a gestão pública, não existindo nenhum bibliotecário atuando nas escolas municipais, havendo somente professores readaptados a frente das bibliotecas. Isso se revela algo preocupante, pois, por não ser o profissional certo para exercer a função, muitas vezes não há o empenho e nem interesse em fazer com que o espaço funcione de maneira correta, fazendo com que não desperte o interesse por parte do aluno e da comunidade escolar.

\section{REFERÊNCIAS}

AMATO, Miriam; GARCIA, Neise Aparecida Rodrigues. A biblioteca na escola. In: GARCIA, Edson Gabriel (Org.). Biblioteca escolar: estrutura e funcionamento. São Paulo: Edições Loyola, 1989. p. 9. 
BRASIL. Lei $\mathbf{n}^{\mathbf{0}}$ 12.244, de 24 de maio de 2010. Dispõe sobre a universalização das bibliotecas nas instituições de ensino do País. 2010. Disponivel em: https://www2.camara.leg.br/legin/fed/lei/2010/lei-12244-24-maio-2010-606412publicacaooriginal-127238-pl.html. Acesso em: 16 maio 2021.

BEHR, Ariel. Gestão da biblioteca escolar: metodologias, enfoques e aplicação de ferramentas de gestão e serviços de biblioteca. Revista Eletrônica Ciência da Informação, Brasília v. 37, n. 2, p. 32-42, maio/ago. 2008.

CARVALHO SILVA, Jonathas Luiz. Uma análise sobre a identidade da Biblioteconomia: perspectivas históricas e objeto de estudo. Olinda: Edições Baluarte, 2010. 99p.

CRUZ NETO, O. O trabalho de campo como descoberta e criação. In: MINAYO, M.C.S. (org.). Pesquisa social: teoria, método e criatividade. Rio de Janeiro: Vozes, 1994. p. 51-66.

GRANADOS MOLINA, Carlos E. CRM (Customer Relationship Management) y servicios de informacion: la biblioteca como un negocio de la nueva economía. Biblios, v.15, n.10, p.1-20, Nov, 2001.

GIL, Antônio Carlos. Métodos e técnicas da pesquisa social. 6. ed. São Paulo: Atlas, 2008.

KIRK, J.; MILLER, M, L. Reliabily and validity in qualitative research. 2.ed. Califórnia: SAGE, 1986.

KUHLTHAU, Carol. Como Usar a Biblioteca na escola: um programa de atividades para o ensino fundamental. 3. ed. Belo Horizonte: Autêntica, 2013.

LIMA, Antonia Lucineide Francisco. Necessidades de informação dos usuários da biblioteca Manoel Bandeira. 53f. Monografia (Graduação em Biblioteconomia) - Universidade Federal da Paraíba, João Pessoa,2014.

LIMA, Patrícia Kellen da Silva. Profissionais da informação bibliotecário e arquivista: quais são suas semelhanças e diferenças. 2013. 90f. Monografia (Graduação em Biblioteconomia) UNIFOR - MG, Minas Gerais, 2013.

MARQUES, Ana Luísa dos Santos. Arte, ciência e história no livro português do século XVIII. 2014. 505 f. Tese (Doutorado em Belas-Artes, na especialidade de Ciências da Arte) Universidade de Lisboa, Lisboa, 2014.

MINAYO, M.C.S. O desafio do conhecimento: pesquisa qualitativa em saúde. Rio de Janeiro (SP/RJ): Hucitec, 2000.

ORGANIZAÇÃO DAS NAÇÕES UNIDAS PARA A EDUCAÇÃO, A CIÊNCIA E A CULTURA. "School Libraries Guidelines". 2011. Disponivel em: www.ifla.org/VII/s11/pubs/school-guidelines.htm. Acesso em: a 15 de nov. 2018.

PERUCCHI, Valmira. Importância da biblioteca nas escolas públicas municipais de criciúma Santa Catarina. Revista ACB: biblioteconomia em Santa Catarina, Florianópolis, V. 4, N. 4, p.80-97, 1999. 
: INOVAÇÃo

ROCHA, Marisa Perrone Campos. A questão da cidadania na sociedade da Informação. Ciência da Informação, Brasília, v. 29, n. 1, p. 40-45, jan./abr.2000.

WALTER, Maria Tereza Machado Teles; BAPTISTA, Sofia Galvão. Formação profissional do bibliotecário. Encontros Bibli: revista eletrônica de biblioteconomia e ciência da informação, v. 13, n. 25, p. 84-103, 2008. 